\title{
Fast Microchip Electrophoresis Using Field Strength Gradients for Single Nucleotide Polymorphism Identification of Cattle Breeds
}

\author{
Doori Oh, Il Cheong Cheong, ${ }^{\dagger}$ Hee Gu Lee, ${ }^{\ddagger}$ Seong Kug Eo,${ }^{\S}$ and Seong Ho Kang ${ }^{*}$ \\ Department of Chemistry and Research Institute of Physics and Chemistry (RINPAC), Chonbuk National University, \\ Jeonju 561-756, Korea. ${ }^{*}$ E-mail: shkang@jbnu.ac.kr \\ ${ }^{\dagger}$ Hankyong National University, Ansung 456-749, Korea \\ ${ }^{\star}$ Medical Genomic Research Center, Korea Research Institute of Bioscience and Biotechnology (KRIBB), \\ Daejeon 305-333, Korea \\ ${ }^{\S}$ Department of Microbiology, College of Veterinary Medicine and Bio-Safety Research Institute, \\ Chonbuk National University, Jeonju 561-756, Korea \\ Received January 12, 2010, Accepted May 5, 2010
}

\begin{abstract}
A microchip electrophoresis (ME) method was developed using a programmed field strength gradients (PFSG) for the single nucleotide polymorphism (SNP) based fast identification of cattle breeds. Four different Korean cattle (Hanwoo) and Holstein SNP markers amplified by allele-specific polymerase chain reaction were separated in a glass microchip filled with $0.5 \%$ poly(ethyleneoxide) $\left(M_{\mathrm{r}}=8000000\right)$ by PFSG as follows: $750 \mathrm{~V} / \mathrm{cm}$ for $0-14 \mathrm{~s}, 166.7 \mathrm{~V} / \mathrm{cm}$ for 14 $31 \mathrm{~s}, 83.3 \mathrm{~V} / \mathrm{cm}$ for $31-46 \mathrm{~s}$, and $750 \mathrm{~V} / \mathrm{cm}$ for $46-100 \mathrm{~s}$. The cattle breeds were clearly distinguished within $45 \mathrm{~s}$. The ME-PFSG method was 7 times and 5 times faster than the constant electric field ME method and the capillary electrophoresis-PFSG method, respectively, with a high resolving power $\left(R_{\mathrm{S}}=5.05-9.98\right)$. The proposed methodology could be a powerful tool for the fast and simultaneous determination of SNP markers for various cattle breeds with high accuracy.
\end{abstract}

Key Words: Cattle breed, Microchip gel electrophoresis, Field strength gradients, Fast separation, Single nucleotide polymorphism (SNP)

\section{Introduction}

The identification of the cattle breeds that are used in various types of foods is of particular importance because of fraudulent processed meat. The quality and safety of food has become a topic of increasing general concern. The ability to definitively distinguish the breed is vital in food safety in order to track disorders such as transmissible spongiform encephalopathies. ${ }^{1}$ Most cattle breeds have a unique coat color pattern that distinguished these cattle breed from each other. ${ }^{2}$ However, processed meat that is derived from cattle can not easily be identified using the coat color pattern. Therefore, fast and accurate analytical methods are required in order to identify the cattle breeds using scientific analysis.

Recently, microchip electrophoresis (ME) has risen above all of the other electrophoresis methods because of its basic theory based on capillary electrophoresis (CE). ME maintains all of the advantages of $\mathrm{CE}$ and exhibits an advanced separation efficiency over a short analysis time. ${ }^{3,4} \mathrm{ME}$ is an excellent alternative to traditional gel electrophoresis or other electrophoresis techniques for the rapid separation of DNA fragments. ${ }^{5}$ The electric field has a twofold effect on the peak width in the open tubular capillary or microchannel with inner diameter of 50 - 100 $\mu \mathrm{m}$. Increasing the electric field decreases the diffusion because of the shorter run times, but at the same time, the higher electric field increases the peak dispersion through increased Joule heating. ${ }^{6}$ The high electric fields also reduces the spacing between the bands with a concomitant resolution loss. The resulting tradeoff between the speed and resolution is a very important practical aspect of the high electric field separations. ${ }^{7}$ Therefore, an optimum electric field must be found by with minimizing the resolution loss for each DNA size in the gel electrophoretic separation.

In the microchip gel electrophoresis of DNA, the electrophoretic velocity $(v)$ can be expressed as the product of the electric field $(E)$ and the electrophoretic mobility $(\mu)$ of DNA molecule at a given field strength when a uniform electric field is applied under steady-state conditions: ${ }^{8,9}$

$$
v=\mu E
$$

However, according to Guttam et al., ${ }^{10}$ this equation can be modified when a non-uniform field $[E(t)]$ is applied because the electrophoretic mobility of the DNA molecule is a function of the electric field $[\mu(E)] .{ }^{11}$

$$
v(t)=\mu(E) \cdot E(t)
$$

Equation (2) states that the actual velocity, $v(t)$, of a DNA molecule is influenced by the field strength at a given time and the mobility, which is also a function of the field strength. Thus, the electrophoretic acceleration $(a)$ can be expressed as the change in the electrophoretic velocity when a non-uniform electric field is applied.

$$
a=\mathrm{d} v / \mathrm{d} t=\mathrm{d}(\mu E) / \mathrm{d} t
$$

In this equation, $\mathrm{d} v$ and $\mathrm{d} t$ are the electrophoretic velocity and 
the time increments, respectively.

The theoretical plate number $(N)$ and the resolution $\left(R_{\mathrm{s}}\right)$ are also affected by the temporary field strength. ${ }^{12}$ Thus, after the proper substitutions, the change in the $N$ is a linear function of the acceleration.

$$
\mathrm{d} N / \mathrm{d} t=\mathrm{d} / \mathrm{d} t \cdot(a l / 2 D)=\mathrm{d} / \mathrm{d} t \cdot(\mu E l / 2 D)
$$

In this equation, $l$ is the effective length of the capillary, $D$ is the diffusion coefficient of the solute, $\mu=\left(\mu_{0}+S_{1} E\right)$, and $S_{1}=$ $A+S_{2} n$ (where $A$ is a constant for the given gel-buffer system, $S_{2}$ is the slope of the plot of $S_{1}$ versus $n\left(r^{2}=0.992\right)$, and $n$ is the chain length (bp) of the DNA molecule). ${ }^{10}$ The change in the resolution is proportional to the square root of the acceleration, $\mathrm{d} R_{\mathrm{S}} / \mathrm{d} t \sim \mathrm{d}\left(a^{1 / 2}\right) / \mathrm{d} t$, when a linear field strength gradient is used. However, the use of a programmed field strength gradient (PFSG) considerably increases the resolving power $\left(R_{\mathrm{s}}\right)$ or decreases the separation time without $R_{\mathrm{s}}$ loss because different applied electric fields are necessary for the separation of different size DNA fragments. ${ }^{10,11,13-15}$ In a previous report, Korean cattle called Hanwoo was identified through the simultaneous detection of various single nucleotide polymorphisms (SNP) markers using CE within 4 min under the optimal voltage programming conditions. ${ }^{16}$ In this study, the ME method was established with a combined field strength gradient for the ultrafast identification $(<45 \mathrm{~s})$ of the model Hanwoo and Holstein cattle breeds using a conventional glass microchip.

\section{Experimental Section}

Chemical and reagents. The $1 \times$ TBE buffer $(0.089 \mathrm{M}$ Tris, $0.089 \mathrm{M}$ borate, $0.002 \mathrm{M}$ EDTA, $\mathrm{pH}$ 8.45) was prepared by dissolving a pre-mixed powder (Amresco, Solon, OH, USA) in deionized water. The dynamic coating gel was made with $1.0 \%$ $(\mathrm{w} / \mathrm{v})$ polyvinylpyrrolidone (PVP, $\left.M_{\mathrm{r}}=1000000\right)$ (Polyscience, Warrington, England) in the $1 \times$ TBE buffer containing $0.5 \mu \mathrm{g} /$ $\mathrm{mL}$ ethidium bromide (EtBr, Molecular Probes, Eugene, Oregon, USA). The mixture was shaken for 2 min and left to stand for $2 \mathrm{~h}$ in order to release the bubbles. The sieving matrix was prepared by dissolving $0.5 \%(\mathrm{w} / \mathrm{v})$ of poly(ethyleneoxide) (PEO, $M_{\mathrm{r}}=8000$ 000) (Sigma, St. Louis, MO, USA) in the $1 \times$ TBE buffer with $0.5 \mu \mathrm{g} / \mathrm{mL}$ EtBr with slow stirring overnight. The Korean cattle (Jeongeup, Korea) and Holstein (Michigan, USA) genomic DNA were provided from the Department of Animal Science, Chungbuk National University. The genomic DNA was extracted from the tissue using a QIAamp DNA Micro Kit (Qiagen, Venlo, The Netherland). The $2 \times$ Multiplex PCR Premix and designed primers that were used to amplify the Korean cattle and Holstein SNP markers were purchased from Solgent (Daejeon, Korea). A 100-bp DNA ladder (25 ng/ $\mu \mathrm{L})$ (Invitrogen, CA, Korea) was used to confirm the PCR products length.

DNA and Allele-specific PCR sample preparation. The genomic DNA was isolated from the tissues using a QIAamp DNA Micro Kit, according to the manufacturer's instructions. ${ }^{16}$ The Korean cattle and Holstein SNP markers were amplified using allele-specific PCR (AS-PCR). MC1R 310G del, MC1R 296Y SNP, LM215-1,2 C and LM215-1,2 D primers that were de- signed by Solgent (Deajeon, Korea). The PCR mixture contained $3 \mu \mathrm{L}$ of $50-100 \mathrm{ng}$ template DNA, $20 \mu \mathrm{L}$ of $2 \times$ Multiples PCR Pre-Mix, and $3 \mu \mathrm{L}$ of each primer (MC1R 310G del, MC1R 296Y SNP, LM215-1,2 C and LM215-1,2 D primers, 10 pmole/ $\mu \mathrm{L}$ ), with a total volume of $40 \mu \mathrm{L}$. The PCR was used for the coamplification of both of the specific DNA targets under the same PCR conditions. The PCR was performed in a MyGenie96 Thermal Block (Deajeon, Korea) using the following two temperature protocol. First, the temperature protocol for the MC1R $310 \mathrm{G}$ del and MC1R 296Y SNP primers PCR mixture was 15 min of pre-denaturation at $95^{\circ} \mathrm{C}, 30$ denaturing cycles at $95^{\circ} \mathrm{C}$ for $20 \mathrm{~s}$, annealing at $60^{\circ} \mathrm{C}$ for $40 \mathrm{~s}$ and $72^{\circ} \mathrm{C}$ for $1 \mathrm{~min}$, and then one extension cycle at $72^{\circ} \mathrm{C}$ for $1 \mathrm{~min}$. The second temperature protocol for the LM215-1,2 C and LM215-1,2 D primers PCR mixture was $15 \mathrm{~min}$ of pre-denaturation at $95^{\circ} \mathrm{C}, 35$ denaturing cycles at $95^{\circ} \mathrm{C}$ for $20 \mathrm{~s}$, annealing at $68^{\circ} \mathrm{C}$ for $1 \mathrm{~min}$, and then one extension cycle at $72{ }^{\circ} \mathrm{C}$ for $3 \mathrm{~min}$. The AS-PCR products were analyzed on a glass microchip using the ME system.

Microchip electrophoresis. The microchip electrophoresis (ME) was performed on a DBCE-100 Microchip CE system(Digital Bio Technology Co., Korea) that was equipped with a diode-pumped solid-state laser (excitation at $532 \mathrm{~nm}$ and fluorescence at 605 nm; Power Technology Inc., Little Rock, AZ, USA) and a high-voltage device (DBHV-100, Digital Bio Technology Co., Korea). The microchip was purchased from DBT (CE-ST-A003, Digital Bio Technology Co., Korea), and the injection design was a cross channel (Fig. 1). The chip channel had a width and depth of $90 \mu \mathrm{m}$ and $20 \mu \mathrm{m}$, respectively. The reservoirs were $2.0 \mathrm{~mm}$ in diameter and $1.0 \mathrm{~mm}$ deep. The injection channel length was $8.0 \mathrm{~mm}$ from reservoir 2 to reservoir 4 , and the separation channel length was $60 \mathrm{~mm}$ from reservoir 1 to 3 . The detection was carried out $30 \mathrm{~mm}$ from the injectioncross. The ME running buffer was a $1 \times \mathrm{TBE}$ buffer with $0.5 \mu \mathrm{g} /$

(A)

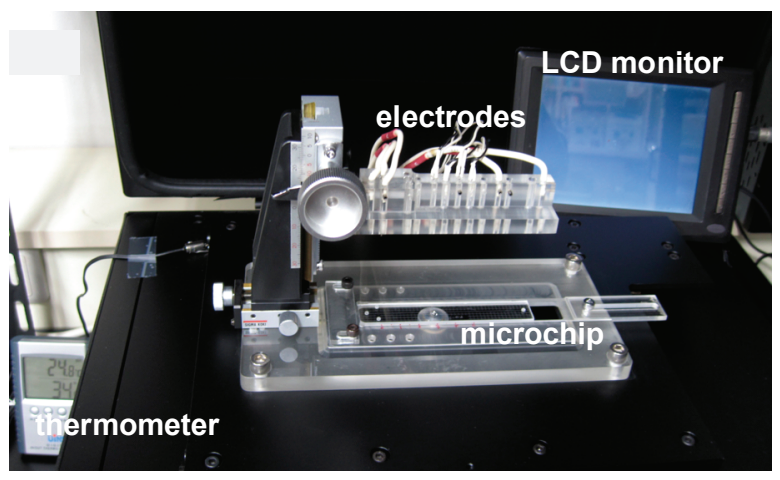

(B)

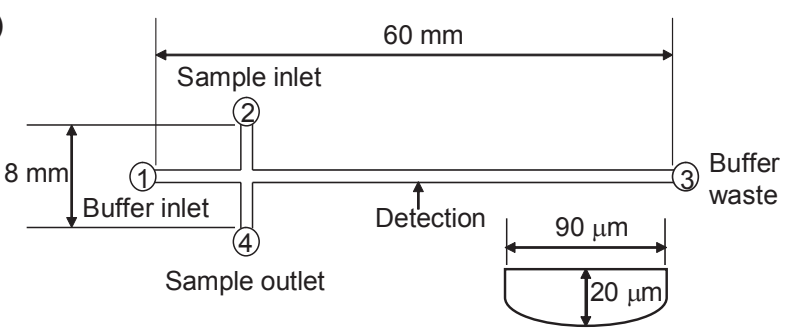

Figure 1. (A) Microchip electrophoresis system and (B) schematic diagram of the cross-T glass microchip. 
$\mathrm{mL}$ EtBr. The coating and sieving matrixes were 1.0\% PVP $\left(M_{\mathrm{r}}=1000000\right), 0.5 \%$ PEO $\left(M_{\mathrm{r}}=8000000\right)$ and each was dissolved in $1 \times \mathrm{TBE}$ buffer with $0.5 \mu \mathrm{g} / \mathrm{mL}$ EtBr. The samples were injected into injection-cross region through a conventional electrokinetic injection at an applied potential of $480 \mathrm{~V}$ in sample outlet reservoir 4 and by grounding in sample inlet reservoir 2 for $60 \mathrm{~s}$. An electric field ranging from 50 to $333.3 \mathrm{~V} / \mathrm{cm}$ was ap-

(A)

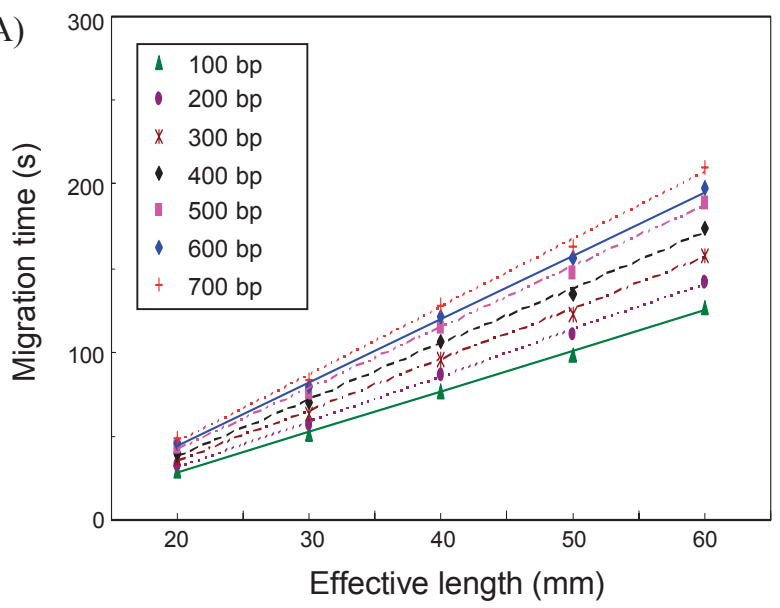

(C)

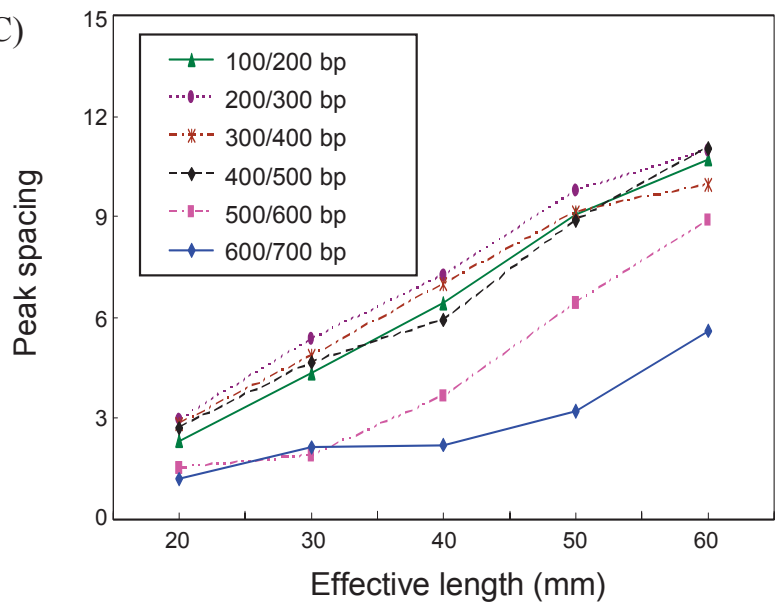

(E)

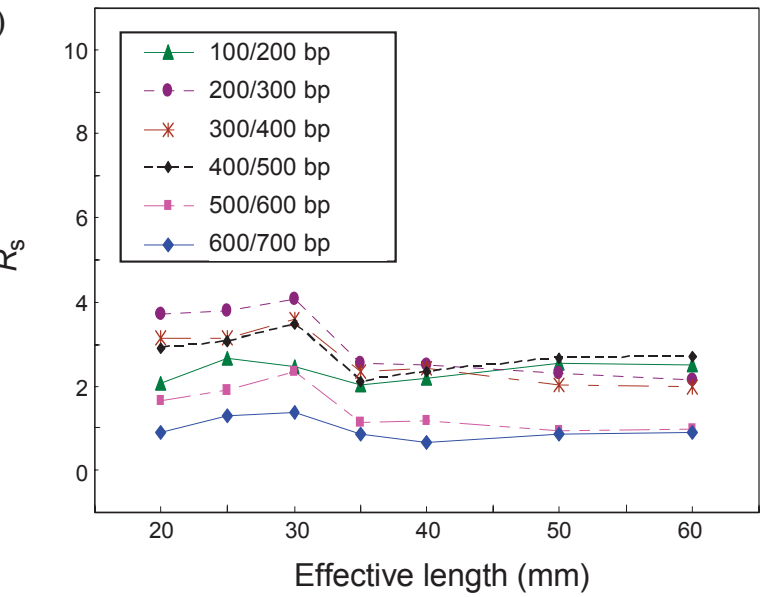

plied at buffer inlet reservoir 1 and sample outlet reservoir 4 .

\section{Results and Discussion}

Various factors such as the effective length, sieving gel, and electric field were examined in order to determine the optimal ME conditions. The separation of the 100-bp DNA ladder as a

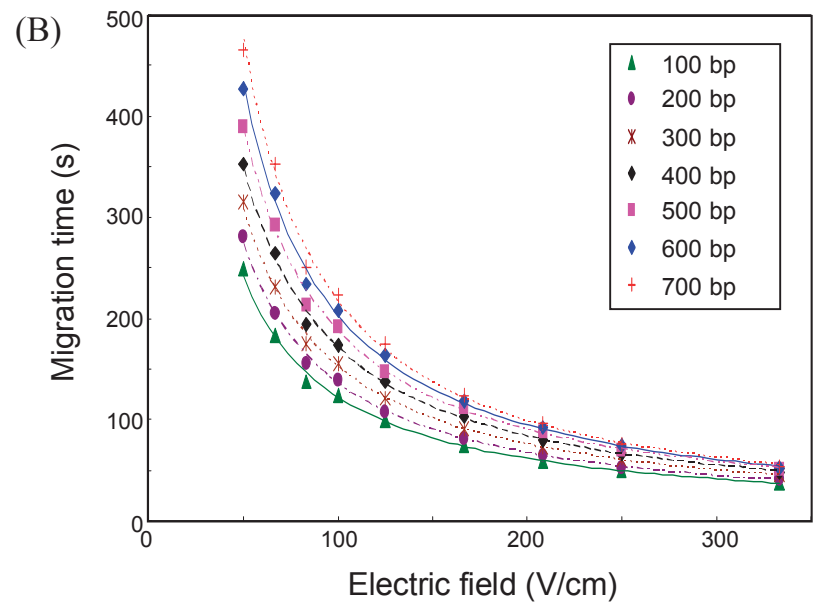

(D)
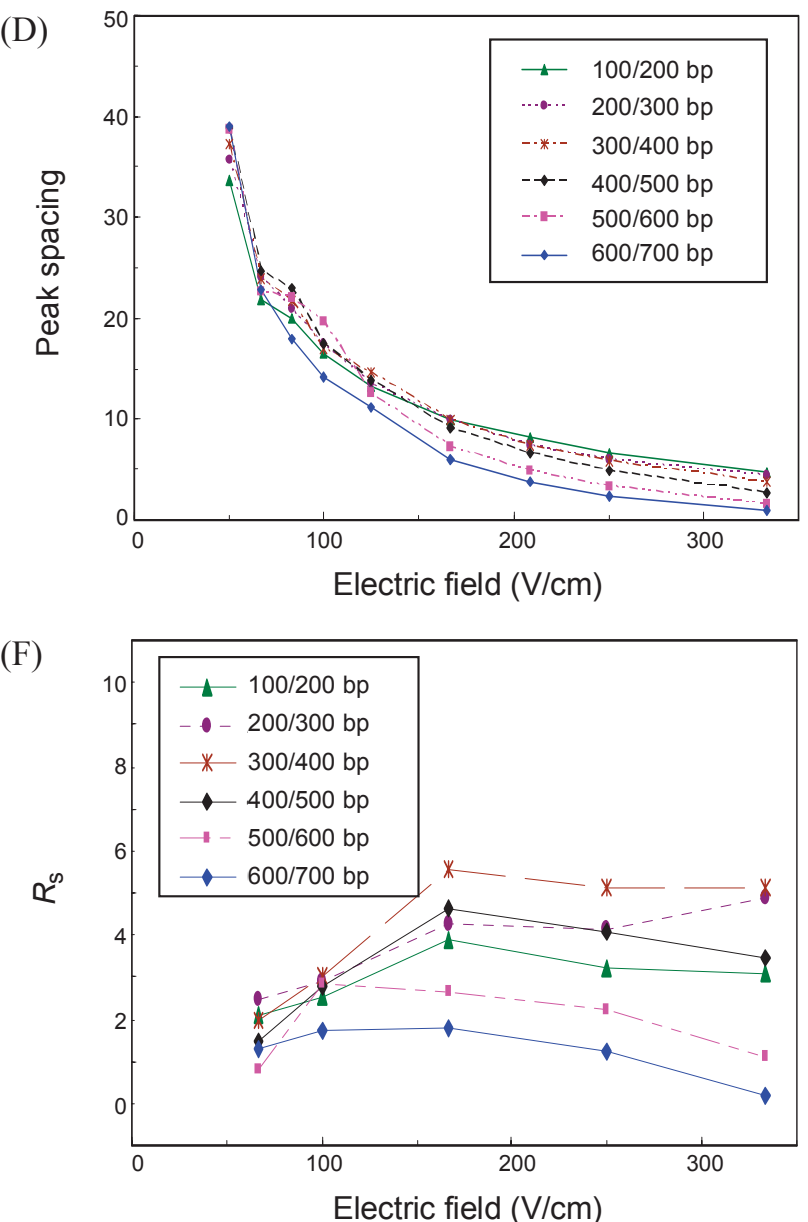

Figure 2. Migration times of the 100 - 700 bp DNA fragments as a function of the effective length (A) and the applied electric field strength (B). The dependences of the peak spacing on the effective length $(C)$ and the electric field strength (D). The effects of the effective length of the microchip (E) and the electric field $(\mathrm{F})$ on the resolution $\left(R_{\mathrm{s}}\right)$. ME applied separation voltage, from 50.0 to $333.3 \mathrm{~V} / \mathrm{cm}$; the running buffer, $1 \times \mathrm{TBE}$ buffer (pH 8.35) with $0.5 \mathrm{ppm}$ EtBr coating gel matrix, 1.0\% PVP $\left(M_{\mathrm{r}}=1000000\right)$; sieving gel matrix, $0.5 \%$ PEO $\left(M_{\mathrm{r}}=8000\right.$ 000); sample, $100-\mathrm{bp}$ DNA ladder fragments (100 bp - $700 \mathrm{bp})$. 
Table 1. Resolution $\left(R_{\mathrm{s}}\right)$ of the $100 / 200,200 / 300$, and $600 / 700$ bp DNA fragments at various sieving matrix concentrations

\begin{tabular}{cccc}
\hline \multirow{2}{*}{ PEO (\%) } & \multicolumn{3}{c}{${ }^{a} R_{\mathrm{s}}($ mean $\pm \mathrm{SD})$} \\
\cline { 2 - 4 } & $100 / 200 \mathrm{bp}$ & $200 / 300 \mathrm{bp}$ & $600 / 700 \mathrm{bp}$ \\
\hline 0.1 & - & - & - \\
0.3 & $2.46 \pm 0.31$ & $2.77 \pm 0.28$ & $2.65 \pm 0.41$ \\
0.5 & $3.84 \pm 0.80$ & $6.78 \pm 0.85$ & $3.85 \pm 0.45$ \\
0.7 & $5.76 \pm 0.72$ & $7.75 \pm 0.72$ & $5.25 \pm 0.20$ \\
0.9 & $6.32 \pm 0.47$ & $8.82 \pm 0.23$ & $3.52 \pm 0.52$ \\
\hline
\end{tabular}

${ }^{a} R_{\mathrm{s}}=\Delta \mathrm{t} / \mathrm{W}_{\text {ave }}$ ( $\Delta \mathrm{t}$ is the difference in the migration time between the two adjacent peaks; $\mathrm{W}_{\text {ave }}$ is the average peak width of the baseline). Applied separation electric field strength, $83.3 \mathrm{~V} / \mathrm{cm}$. The other ME conditions are the same as in Fig. 2.

size marker was examined for various PEO $\left(M_{\mathrm{r}}=8000000\right)$ concentrations from $0.1-0.9 \%$ using a constant electric field strength of $83.3 \mathrm{~V} / \mathrm{cm}$ (Table 1) in order to determine the most suitable concentration with respect to the migration time of the target DNA fragments and the resolution. A better resolution was observed at higher PEO concentration for the separation of the 100-bp DNA ladder. However, the gel viscosity was high at the larger concentrations, causing long separation times. As a result, the optimal PEO concentration of $0.5 \%(\mathrm{w} / \mathrm{v})$ was selected for the fast identification of Hanwoo. An increased microchip effective length also expanded the peak spacing (Figs. 2A and 2C). However, very long effective lengths led to an extended analysis time and poor resolution as well as peak broadening (Fig. 2E). Therefore, considering the analysis time and the $R_{\mathrm{s}}$, an effective length of $3 \mathrm{~cm}$ was selected as the optimal length. The effects of the migration time and $R_{\mathrm{S}}$ were examined for electric fields ranging from $50-333.3 \mathrm{~V} / \mathrm{cm}$ in order to estimate the appropriate electric field strength (Figs. 2B, 2D and 2F). The migration times and the peak spacing of the DNA fragments were inversely proportional to the electric field strength. However, very large electric fields resulted in peak broadening poor $R_{\mathrm{S}}$ (Fig. 2F).

These results confirmed the theory of the electrophoresis was correlated to the electric field, because the electrophoretic migration velocity was directly proportional to the electric field, and the highest electric field strengths exhibited the shortest separation time. ${ }^{9}$ However, very high electric field strengths were not appropriate for the target DNA fragments with specific lengths because of the high temperature in the microchip, which diversified the axial temperature leading to the peak broadening, the reduced $R_{\mathrm{s}}$, and the lower reproducibility. 17,18

The target DNA fragments (100 - $700 \mathrm{bp})$ were examined at a low constant electric field (LCFS) of $83.3 \mathrm{~V} / \mathrm{cm}$ and a high constant electric field (HCFS) of $833.3 \mathrm{~V} / \mathrm{cm}$ in order to better visualize the effects of the electric field strength. Initially, for the LCFS, the 100-bp DNA ladders were separated in $350 \mathrm{~s}$ with good resolutions $\left(R_{\mathrm{s}} \geq 3.84\right.$ for $100-700 \mathrm{bp}$, Table 1$)$ but an extended analysis time ( $\sim 240 \mathrm{~s}$, Fig. 3A). On the other hand, for the HCFS, all of the DNA fragments were rapidly eluted within $18 \mathrm{~s}$ without a baseline separation (Fig. 3B). Therefore, three different types of field strength gradients systems were designed to overcome these limitations (Figs. 3C - 3E): First, resolutions of
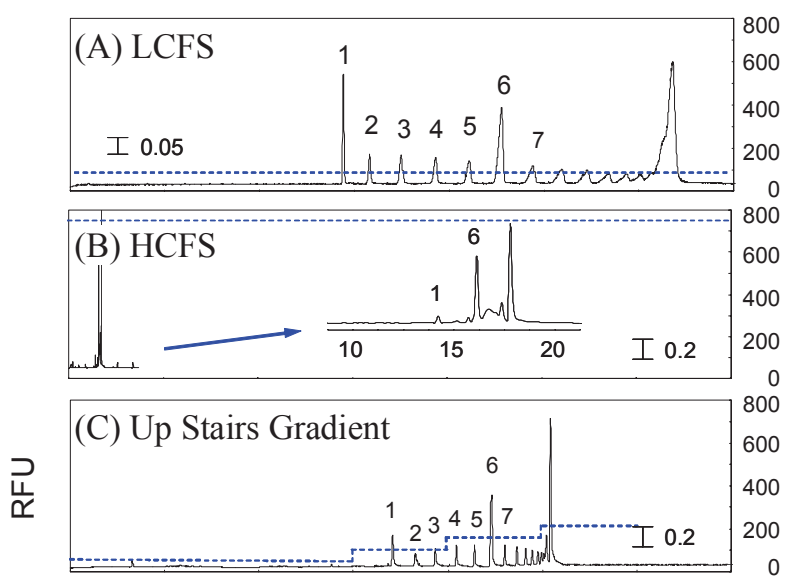

(D) Down Stairs Gradient
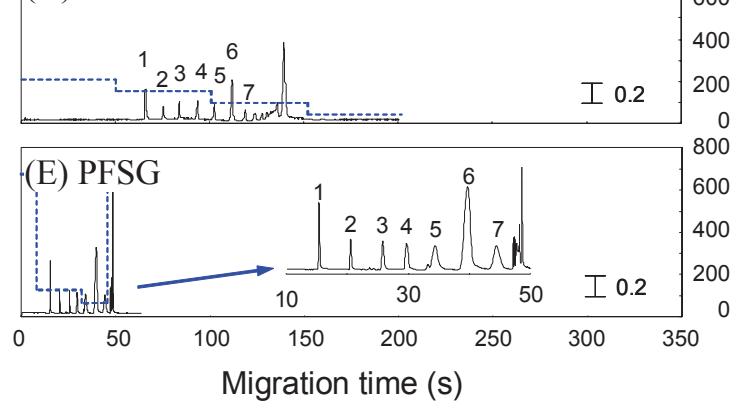

Figure 3. Representative electropherograms of the 100-bp DNA ladder with respected to the electric field strength. Indications: (A) LCFS, low constant field strength; (B) HCFS, high constant field strength; (C) Up stairs gradient; (D) Down stairs gradient; and (E) PFSG, programmed field strength gradient. Applied separation electric field strength, 83.3 $\mathrm{V} / \mathrm{cm}$ for LCFS; $833.3 \mathrm{~V} / \mathrm{cm}$ for HCFS; $750 \mathrm{~V} / \mathrm{cm}$ for 0 to $14 \mathrm{~s}, 166.7$ $\mathrm{V} / \mathrm{cm}$ for 14 to $31 \mathrm{~s}, 83.3 \mathrm{~V} / \mathrm{cm}$ for 31 to $46 \mathrm{~s}, 750 \mathrm{~V} / \mathrm{cm}$ for 46 to 100 $\mathrm{s}$ for PFSG. RFU $=$ relative fluorescence unit. Peaks: $1=100,2=200$, $3=300,4=400,5=500,6=600,7=700 \mathrm{bp}$. The dotted lines represent the applied electric field strength. The other ME conditions are the same as in Fig. 2.

$R_{\mathrm{S}}=3.84-6.78$ were obtained for the DNA fragments with specific lengths (100 - $700 \mathrm{bp}$ ) at a low voltage, and a stepwise increase in the gradient voltage was applied at regular intervals of the electric field and migration time (Fig. 3C). Second, a stepwise decrease in the gradient voltage was applied, and a remarkably fast separation time of $\sim 110 \mathrm{~s}$ was obtained (Fig. $3 \mathrm{D})$. The results showed the need for an appropriate voltage program during the separation of target DNA fragments with different lengths. Fig. 3E shows a well designed, programmed field strength gradient (PFSG) based on the combination of the LCFS and the HCFS. Excellent resolutions $\left(R_{\mathrm{S}}>2.7\right)$ were obtained without increasing the analysis time using the following PFSG procedure. The portions were retrenched prior to the first DNA peak (100 bp) and following the last DNA peak (700 bp) using the HCFS. Additionally, the portion between the two DNA fragments (from $100 \mathrm{bp}$ to $700 \mathrm{bp}$ ) in the region of interest was applicable at a reduced electric field for the LCFS. The PFSG was easily designed, and the separation occurred within $90 \mathrm{~s}$. However, Fig. 3A shows a high enough resolution for the 100 $700 \mathrm{bp}$ DNA at $83.3 \mathrm{~V} / \mathrm{cm}$. Therefore, an additional step could decrease the separation time. Thus, the electric field was slightly increased from $83.3 \mathrm{~V} / \mathrm{cm}$ to $166.7 \mathrm{~V} / \mathrm{cm}$ in the range from 100 - 


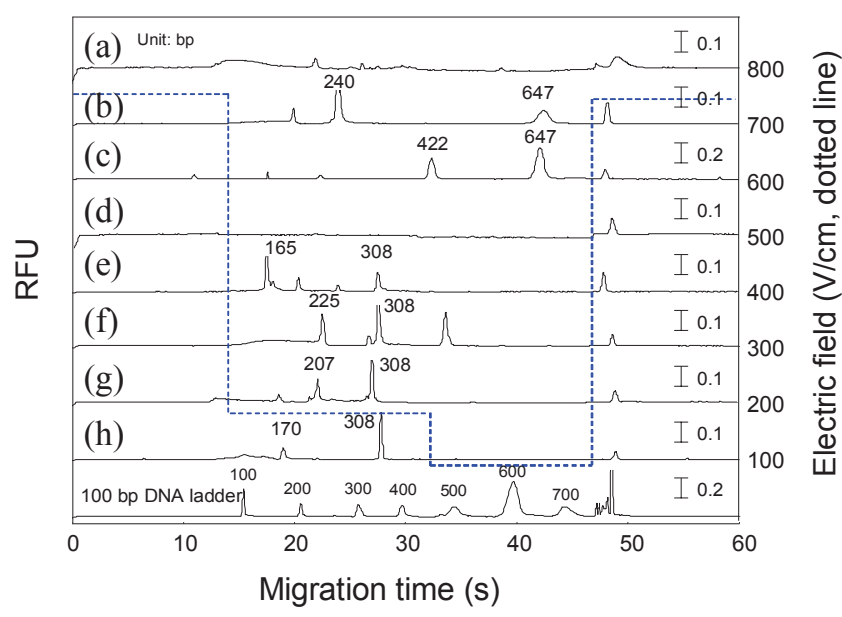

Figure 4. Representative electropherograms of the amplified Korean cattle (Hanwoo) and Holstein SNP markers using the ME-PFSG method. ME separation conditions: sample separation electric field, applied separation electric field strength, $750 \mathrm{~V} / \mathrm{cm}$ for 0 to $14 \mathrm{~s}, 166.7 \mathrm{~V} / \mathrm{cm}$ for 14 to $31 \mathrm{~s}, 83.3 \mathrm{~V} / \mathrm{cm}$ for 31 to $46 \mathrm{~s}, 750 \mathrm{~V} / \mathrm{cm}$ for 46 to $100 \mathrm{~s}$ for PFSG, (a) =LM215-1,2 D Holstein; (b) = LM215-1,2 D Hanwoo; (c) = LM215-1,2 C Holstein; (d) = LM215-1,2 C Hanwoo; (e) = MC1R 296Y SNP Holstein; (f) = MC1R 296Y SNP Hanwoo; (g) = MC1R 310G del Holstein; $(\mathrm{h})=$ MC1R $310 \mathrm{G}$ del Hanwoo. The dotted line represents the applied electric field strength. The other ME conditions are the same as in Fig. 3.

Table 2. Comparison of the migration time and the resolution of the Hanwoo and Holstein SNP markers under the optimal ME-PFSG conditions

\begin{tabular}{|c|c|c|c|}
\hline SNP marker & DNA (bp) & Migration time $^{a}(\mathrm{~s})$ & $R_{\mathrm{s}}^{b}$ \\
\hline MC1R 310G del & 170 & $19.77 \pm 0.11$ & \multirow{2}{*}{$8.52 \pm 0.27$} \\
\hline Korean cattle & 308 & $26.88 \pm 0.51$ & \\
\hline MC1R 310G del & 207 & $21.73 \pm 0.22$ & \multirow{2}{*}{$5.07 \pm 0.19$} \\
\hline Holstein & 308 & $26.65 \pm 0.18$ & \\
\hline MC1R 296Y SNP & 225 & $23.38 \pm 0.16$ & \multirow{2}{*}{$4.97 \pm 0.25$} \\
\hline Korean cattle & 308 & $27.09 \pm 0.50$ & \\
\hline MC1R 296Y SNP & 165 & $16.47 \pm 0.28$ & \multirow{2}{*}{$9.98 \pm 0.17$} \\
\hline Holstein & 308 & $27.02 \pm 0.43$ & \\
\hline LM215-1, 2 C & 422 & $31.87 \pm 0.43$ & \multirow{2}{*}{$5.05 \pm 0.40$} \\
\hline Holstein & 647 & $42.38 \pm 0.26$ & \\
\hline LM215-1, 2 D & 240 & $23.73 \pm 0.09$ & \multirow{2}{*}{$9.06 \pm 0.22$} \\
\hline Korean cattle & 647 & $42.51 \pm 0.39$ & \\
\hline
\end{tabular}

${ }^{a}$ Migration time $=$ Mean \pm standard deviation $(n=3) .{ }^{b} R_{\mathrm{s}}=2\left(\mathrm{t}_{2}-\mathrm{t}_{1}\right) /\left(\mathrm{w}_{1}+\mathrm{w}_{2}\right)$, where $t_{1}, t_{2}, w_{1}$, and $w_{2}$ are the migration time and the peak width of the adjacent DNA peaks $(n=5)$. The ME conditions are the same as in Fig. 4.

$700 \mathrm{bp}$. The separation using the four steps PFSG reduced the migration time to $45 \mathrm{~s}$ with excellent resolutions $\left(R_{\mathrm{s}}>2.7\right)$. The PFSG was programmed to the best separation conditions for all of the DNA fragments of interest including the amplified SNP markers for the cattle.

Fig. 4 shows that all of the electropherograms for the AS-PCR products of Hanwoo with different DNA lengths (i.e., 165 - 647 bp) were separated within $45 \mathrm{~s}$ under the following optimal voltage programming conditions: $750 \mathrm{~V} / \mathrm{cm}$ for $0-14 \mathrm{~s}, 166.7 \mathrm{~V} / \mathrm{cm}$ for $14-31 \mathrm{~s}, 83.3 \mathrm{~V} / \mathrm{cm}$ for $31-46 \mathrm{~s}$, and $750 \mathrm{~V} / \mathrm{cm}$ for $46-100$ s. After the successful detection of the Hanwoo and Holstein samples under the optimal separation conditions, the ME results showed a $100 \%$ correlation for the cattle samples. ${ }^{16}$ The MEPFSG method was 7 times and 5 times faster than the constant electric field method and the previously reported CE-PFSG method, ${ }^{16}$ respectively (Table 2 ), with a high resolving power $\left(R_{\mathrm{s}}=5.05-9.98\right)$. In conclusion, a ME method was developed using field strength gradients for the fast identification of model Hanwoo and Holstein cattle breeds with a high accuracy and resolving power. The ME assay successfully identified the cattle breeds in the paragon samples of the cattle SNP markers. Although this study describes the difference between the Korean cattle and Holstein as the model of cattle breeds, the simultaneous detection of various different specific DNA fragments of Korean cattle AS-PCR primers (i.e. MC1R 310G del, MC1R 296Y SNP, LM215-1,2 C and LM215-1,2 D) shows the high accuracy of identification $(\sim 97.5 \%)$ from other cattle breeds. ${ }^{4,19}$ Therefore, this ME-PFSG technique could be a powerful tool for the ultra-fast and simultaneous determination of SNP markers for various cattle breeds with high accuracy.

Acknowledgments. This work was supported by a grant (Code 20070501034006) from the BioGreen 21 Program, Rural Development Administration, Republic of Korea.

\section{References}

1. Gielbert, A.; Davis, L. A.; Sayers, A. R.; Hope, J.; Gill, A. C.; Sauer, M. J. J. Mass. Spectrom. 2000, 33, 384.

2. Do, K. T.; Shin, H. Y.; Lee, J. H.; Kim, N. S.; Park, E. W.; Yoon, D. H.; Kim, K. S. J. Anim. Sci. \& Technol. 2007, 49, 711.

3. Kim, D.-K.; Kang, S. H. J. Chromatogr. A 2005, 1064, 121.

4. Lee, M.; Yoon, D.; Jeon, J.-T.; Eo, S. K.; Kang, S. H. Bull. Korean Chem. Soc. 2009, 30, 2655.

5. Jeon, S.; Eo, S. K.; Kim, Y.; Yoo, D. J.; Kang, S. H. Talanta 2007, 73,415 .

6. Heller, C. Electrophoresis 2000, 21, 593.

7. Luckey, J. A.; Smith, L. M. Anal. Chem. 1993, 65, 2841.

8. Guttman, A.; Cooke, N. J. Chromatogr. 1991, 559, 285.

9. Baker, D. R. Capillary Electrophoresis; John Wiley \& Sons: New York, 1995; pp 31-52.

10. Guttman, A.; Wanders, B.; Cooke, N. Anal. Chem. 1992, 64, 2348.

11. Guttman, A.; Cooke, N. Anal. Chem. 1991, 63, 2038.

12. Karger, B. L.; Cohen, A. S.; Guttman, A. J. Chromotogr. 1989, 492, 585.

13. Demana, T.; Lanan, M.; Morris, M. D. Anal. Chem. 1991, 63, 2795.

14. Yoshida, C.; Endo, Y.; Baba, Y. Eur. J. Pharm. Sci. 2001, 13, 99.

15. Inoue, H.; Tsuhako, M.; Baba, Y. J. Chromatogr. A 1998, 802, 179.

16. Go, H.; Lee, M.; Oh, D.; Kim, K.-S.; Cho, K.; Yoo, D. J.; Kang, S. H. Bull. Korean Chem. Soc. 2009, 30, 2141.

17. Tang, G.; Yan, D.; Yang, C.; Gong, H.; Chai, J. C.; Lam, Y. C. Electrophoresis 2006, 27, 628.

18. Evenhuis, C. J.; Haddad, P. R. Electrophoresis 2009, 30, 897.

19. Negrini, R.; Nicoloso, L.; Crepaldi, P.; Milanesi, E.; Colli, L.; Chegdani, F.; Pariset, L. et al. Anim. Genet. 2009, 40, 18. 